Revista Destaques Acadêmicos, Lajeado, v. 8, n. 3, 2016. ISSN 2176-3070

DOI: http://dx.doi.org/10.22410/issn.2176-3070.v8i3a2016.1182

www.univates.br/revistas

\title{
AVALIAÇÃO DOS RISCOS OCUPACIONAIS DOS TRABALHADORES DO ATERRO SANITÁRIO DO MUNICÍPIO DE SOBRAL/CE
}

\author{
Leidy Dayane Paiva de Abreu ${ }^{1}$, Ana Hirley Rodrigues Magalhães², \\ Raquel Xavier Guimarães ${ }^{3}$, Glícia Mesquita Martiniano Mendonça ${ }^{4}$, \\ Francisca Emanuela Paiva de Abreu ${ }^{5}$, Lívia Alves de Souza ${ }^{6}$
}

\begin{abstract}
Resumo: A destinação final dos resíduos sólidos é uma tarefa difícil, muitas vezes coloca os profissionais que atuam diretamente nessa função em condições de riscos de trabalho. Este estudo tem o objetivo de avaliar os possíveis riscos ocupacionais que estão sujeitos os trabalhadores do aterro sanitário do município de Sobral/CE. O estudo foi desenvolvido com aplicação de questionário que envolve possíveis riscos socioambientais e avaliação em campo, por meio da visita in loco. Pôde-se identificar a presença de diversos riscos a que os trabalhadores do aterro sanitário estão sujeitos por falta de conhecimento sobre os tipos de resíduos que eles trabalham, não uso dos Equipamentos de Proteção Individual, falta de estrutura para segurança dos profissionais e exposição a doenças ocupacionais. Por meio do estudo, foram sugeridas recomendações para melhoria quanto à saúde e condições de trabalho da categoria.
\end{abstract}

Palavras-chave: Saúde. Resíduos Sólidos. Segurança do Trabalho.

1 Enfermeira, Mestrando do Programa Cuidados Clínicos em Enfermagem e Saúde da Universidade Estadual do Ceará (UECE), Fortaleza-CE. E-mail: dayannepaiva@hotmail.com.

2 Enfermeira, Mestranda da Rede Nordeste de Formação em Saúde da Família da Universidade Estadual Vale do Acaraú - UVA (Nucleadora), Sobral-CE. E-mail: ana_magalhaes@hotmail.com.

3 Enfermeira, Mestranda da Rede Nordeste de Formação em Saúde da Família da Universidade Estadual Vale do Acaraú - UVA (Nucleadora), Sobral-CE. E-mail: raquelguimaraesponte@hotmail.com.

4 Enfermeira, Mestrando do Programa Cuidados Clínicos em Enfermagem e Saúde da Universidade Estadual do Ceará (UECE), Fortaleza-CE. E-mail: glicia_martiniano@hotmail.com.

5 Estudante de Serviço Social do Instituto Superior de Teologia Aplicada (INTA), Sobral-CE. E-mail: manu.rio@hotmail.com.

6 Administradora, Estudante de Pós-graduação em Gestão Ambiental pelo Instituto Federal de Educação, Ciência e Tecnologia (IFCE), Campus Sobral-CE. E-mail: livia_souza@hotmail.com. 


\section{INTRODUÇÃO}

Sabe-se que por muitos anos os resíduos sólidos eram comparados como algo descartável e sem valor, e sua destinação era feita sem os devidos cuidados, sendo lançados direto no meio ambiente, causando impactos negativos. Podese observar que ainda hoje, essa prática acontece (SILVEIRA, 2009). Devido ao aumento da produção e consumo de produtos industrializados, observa-se um maior descarte de resíduos sólidos no meio urbano, transformando-o em um grande problema da sociedade moderna (ABEQ, 2001).

Os aterros sanitários configuram-se nos dias atuais como uma maneira mais segura de disposição dos resíduos sólidos, exigindo, para sua eficiência e eficácia, que o processo de escolha da sua área seja feito de uma maneira minuciosa e atenta para todos os aspectos que interferem nesse processo (SILVA, 2011).

Segundo Brasil (2012) os resíduos sólidos caracterizam-se como um material, substância, objeto ou bem descartado resultante de atividades humanas em sociedade, a cuja destinação final se procede, se propõe proceder ou se está obrigado a proceder, nos estados sólido ou semissólido, bem como gases contidos em recipientes e líquidos cujas particularidades tornem inviável o seu lançamento na rede pública de esgotos ou em corpos d'água, ou exijam para isso soluções técnicas ou economicamente inviáveis em face da melhor tecnologia disponível. Já os rejeitos são resíduos sólidos que, depois de esgotadas todas as possibilidades de tratamento e recuperação por processos tecnológicos disponíveis e economicamente viáveis, não apresentem outra possibilidade que não a disposição final ambientalmente adequada.

A Lei $n^{\circ} 12.305 / 10$, que institui a Política Nacional de Resíduos Sólidos (PNRS) contém instrumentos importantes para permitir o avanço necessário ao País no enfrentamento dos principais problemas ambientais, sociais e econômicos decorrentes do manejo inadequado dos resíduos sólidos. Prevê a prevenção e a redução na geração de resíduos, tendo como proposta a prática de hábitos de consumo sustentável e um conjunto de instrumentos para propiciar o aumento da reciclagem e da reutilização dos resíduos sólidos (aquilo que tem valor econômico e pode ser reciclado ou reaproveitado) e a destinação ambientalmente adequada dos rejeitos (aquilo que não pode ser reciclado ou reutilizado). Institui a responsabilidade compartilhada dos geradores de resíduos: dos fabricantes, importadores, distribuidores, comerciantes, o cidadão e titulares de serviços de manejo dos resíduos sólidos urbanos na Logística Reversa dos resíduos e embalagens pós-consumo e pós-consumo (BRASIL, 2012).

A destinação final dos resíduos sólidos mostra-se uma tarefa árdua, logo, sujeita os profissionais do aterro à múltiplos riscos ocupacionais. Segundo Neves (2003), trata-se de um dos serviços mais desvalorizados socialmente, 
ainda que seja uma tarefa fundamental para a sociedade, por livrá-la do convívio com doenças e pestes e auxiliar na manutenção da beleza das cidades.

Os trabalhadores deste local estão expostos a vários riscos, como a presença de micro-organismos e as condições físicas do ambiente. Os encarregados de dar o destino aos resíduos desprezados precisam lidar com os agravos desses riscos, muitas vezes resultantes da negligência, do despreparo ou da falta de sensibilização de gestores públicos e privados e da sociedade (SILVEIRA, 2009).

Em relação às ocorrências de doenças e de acidentes ocupacionais, envolvendo exclusivamente os profissionais que trabalham diretamente com a destinação final dos resíduos, lamentavelmente, em países latinoamericanos não existem dados e informações sistematizados sobre acidentes de trabalho. Quanto as doenças relacionadas ao trabalho com resíduos sólidos municipais, as informações praticamente inexistem, ao mesmo tempo em que existem poucos estudos epidemiológicos sobre a saúde dos trabalhadores dos sistemas de gerenciamento de resíduos sólidos municipais, em especial dos que trabalham diretamente com a destinação final, mesmo nos países desenvolvidos (FERREIRA; ANJOS, 2001).

As Normas Regulamentadoras (NR) relativas à segurança do trabalho são de observância obrigatória pelas empresas privadas e públicas e pelos órgãos públicos da administração direta e indireta, bem como pelos órgãos dos Poderes Legislativo e Judiciário, que possuam empregados regidos pela Consolidação das Leis do Trabalho - CLT (BRASIL, 2015). As NR mais comuns para o estudo são: NR 04 - Serviços Especializados em Engenharia de Segurança e em Medicina do Trabalho; NR 06 - Equipamentos de Proteção Individual - EPI; NR 09; NR 11 - Transporte, Movimentação, Armazenagem e Manuseio de Materiais; NR 12 - Máquinas e Equipamentos; NR 15 - Atividades e Operações Insalubres; NR 17 - Ergonomia; NR 21 - Trabalho a Céu Aberto; NR 23 - Proteção Contra Incêndios; NR 24 - Condições Sanitárias e de Conforto nos Locais de Trabalho; NR 26 - Sinalização de Segurança e NRR 5 - Produtos Químicos (BRASIL, 2015).

Embora não existam dúvidas sobre a importância da destinação final dos resíduos sólidos para o meio ambiente e para saúde da comunidade, esta percepção não tem sido traduzida em ações efetivas no que diz respeito a mudanças na situação de segurança e saúde dos trabalhadores do aterro sanitário, pois os mesmos estão diretamente em contato com os resíduos, expondo sua vida e sua saúde a diversos riscos, enfrentando as mais variadas situações, que vão desde cortes em mãos ou pés ocasionadas pela má postura dos usuários, ou até mesmo as condições insalubres.

Esse estudo propõe-se a mostrar os riscos enfrentados pelos profissionais que trabalham com a destinação final dos resíduos sólidos. Riscos estes que podem ser minimizados, ou até eliminados, com propostas e estratégias de melhorias para o órgão que atua diretamente com a destinação final dos 
resíduos. É preciso que atitudes sejam tomadas de forma incisiva pela gestão pública municipal. Assim, é necessário criar um conjunto de medidas visando à minimização dos acidentes na rotina diária, as doenças ocupacionais, bem como proteger a integridade e a capacidade do trabalhador.

A partir disso, esse estudo tem como objetivos avaliar os riscos ocupacionais a que estão sujeitos os trabalhadores do aterro sanitário do município de Sobral/CE; averiguar a disponibilidade e uso de recursos de prevenção de acidentes e doenças ocupacionais, com ênfase nos Equipamentos de Proteção Individual (EPIs), descrever os tipos de resíduos com que os trabalhadores entram em contato e implantar proposta educativa junto aos mesmos que contribua para minimizar os riscos ocupacionais.

\section{METODOLOGIA}

Trata-se de estudo de caso realizado em um aterro sanitário do município Sobral/CE, como pode ser visto no mapa (figura 1), realizado com os trabalhadores que lidam diretamente com os resíduos sólidos do aterro.

Figura 1. Mapa da localização geográfica do aterro sanitário de Sobral/CE

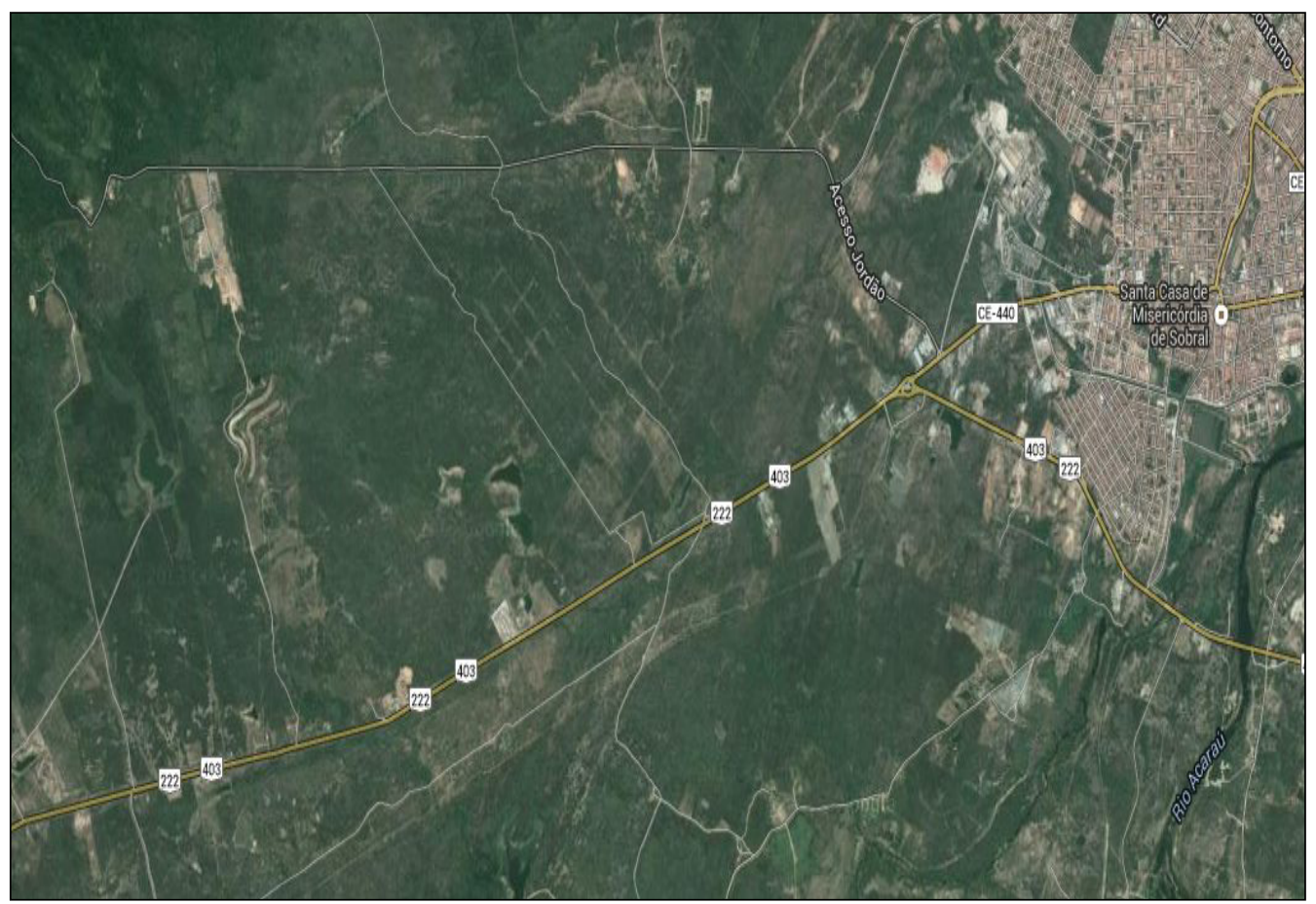

Fonte: Google Earth, 2013

O Município de Sobral está localizado na porção noroeste do Estado do Ceará, a $240 \mathrm{~km}$ da capital Fortaleza, por via da BR-222. A cidade possui 
a quinta maior população do estado, com um número superior a 150.000 habitantes, concentrando-se a maior parte na zona urbana (SOBRAL, 2009). A cidade está localizada no sertão, tem clima tropical, quente e seco e conta com uma área territorial de aproximadamente $1.700 \mathrm{~km}^{2}$. Aproximadamente $20 \%$ da população vivem com menos de um salário mínimo e quase $12 \%$ não tem instrução ou possuem menos de um ano de estudo. No setor saúde, o município é referência para toda Zona Norte do estado, sendo considerado Polo Assistencial da Região (IBGE, 2010).

Sobral/CE se apresenta como o mais significativo referencial de crescimento e desenvolvimento econômico do interior do Estado, vantagem essa que facilita o aumento na produção de resíduos e, principalmente, dos pontos críticos de acúmulo do mesmo. O aterro sanitário do município foi criado em 1999 e passou a funcionar após o término do lixão, que ficava nas proximidades da BR-222, na saída da cidade em direção a Serra da Ibiapaba. $O$ aterro sanitário se localiza no sertão semiárido, no pé da Serra do Rosário, interior de Sobral/ $\mathrm{CE}$, e tem acesso pela via que liga a cidade sede do município ao distrito de Jordão. As origens dos resíduos possuem fontes variadas, além da cidade sede do município, alguns distritos do município destinam seus resíduos no mesmo local, como também, o município de Meruoca (SOBRAL, 2009).

O estudo ocorreu nos meses de agosto de 2012 a outubro de 2013. De acordo com Minayo e Deslandes (2009), devemos traçar um tempo necessário para realização de cada uma das etapas propostas. Foi adotada para coleta de dados a pesquisa documental, assim como a aplicação de um questionário individual e a observação livre "in loco" no aterro sanitário de Sobral/CE, seguindo um roteiro elaborado previamente, com o objetivo de analisar as tarefas e atividades dos trabalhadores de forma holística e imparcial, assim como o ambiente, as condições de trabalho, os tipos de resíduos que os profissionais entram em contato, desde os movimentos do trabalhador, postura, assim como às ferramentas de trabalho e o manejo dos resíduos.

Foi observada a realidade no ambiente em que ocorre o fenômeno, em seu período habitual de funcionamento, e registraram-se os dados à medida que foram ocorrendo espontaneamente. A observação, na definição de Lakatos e Marconi (2010), "é uma técnica de coleta de dados para conseguir informações que utiliza os sentidos na obtenção de determinados aspectos da realidade".

Os dados sobre a destinação final dos resíduos, maquinários utilizados, tipos de resíduos, quantidade, número de funcionários foram obtidos por meio da secretaria de Conservação e Serviços Públicos, que atua diretamente na coleta sistemática e destinação final dos resíduos no município. A avaliação ocorreu por meio dos questionários aplicados para os trabalhadores, explorando os riscos individuais e ocupacionais, e também por meio das informações obtidas do órgão gestor que atua diretamente com a destinação final dos resíduos.

Os dados foram agrupados em categorias e organizados em gráficos, quadro e imagens. Os documentos analisados foram desde a Lei de Criação, 
assim como as licenças de prévia, de instalação e operação, se o aterro está conforme a PNRS (BRASIL, 2012), que traz a disposição dos resíduos desde a coleta até a destinação final, em conformidade com as Leis Trabalhistas.

\section{RESULTADOS E DISCUSSÕES}

\section{Caracterização física e estrutural do aterro sanitário de Sobral/CE}

O aterro sanitário de Sobral possui um solo de boa compactação, de origem cristalina, o que qualifica a área para funcionamento de um aterro. Recebe diariamente 155 toneladas de resíduos. Sabe-se que a maior parte desse material pode ser aproveitado, realizando-se triagem, seleção e destinação correta, sobrando, assim, pouco rejeito ou lixo propriamente dito.

Segundo dados da Secretaria de Conservação e Serviços públicos (SOBRAL, 2009), cada caçamba faz, em média, 03 viagens diárias ao aterro e utiliza-se o método da trincheira para colocar os resíduos, que consiste na abertura de valas no solo onde os resíduos são depositados pelas caçambas. Após, os resíduos são compactados por um trator de esteira e cobertos por uma camada de terra. O método da área também é empregado em locais do aterro onde a topografia se apresenta de forma irregular, usando-se uma área plana para a disposição e a compactação.

$\mathrm{O}$ aterro possui área geral de grande extensão. Segundo dados da Secretaria de Conservação e Serviços Públicos (SOBRAL, 2009) todo o terreno é compactado com manta impermeabilizante de polietileno, conforme as normas de engenharia exigidas por lei. $\mathrm{O}$ aterro possui Estudos de Impactos Ambientais - EIA e Relatório de Impactos Ambientais - RIMA, valas sépticas para os resíduos de origem hospitalar, drenagem de águas pluviais e coleta de esgoto. Com relação aos aspectos legais, deverão ser avaliados: Lei de Uso e Ocupação do Solo, Código de Posturas, Código de Obras, Plano Diretor (CORREA; LANÇA, 2008), entre outros.

Durante a visita in loco observou-se a presença de uma pá mecânica, um trator de esteiras para compactação do material, retroescavadeira, um caminhão basculante e caçambas para recobrimento do lixo com uma camada de terra ao final de cada jornada de trabalho. A maioria dos equipamentos estavam em precárias condições, não funcionavam de maneira adequada e outros estavam quebrados.

Para municípios de pequeno porte e de poucos recursos, a disponibilidade de equipamentos para a operação de um aterro é fator limitante, logo tratores de esteira têm custos de aquisição e de manutenção elevados. Além do que o menor trator disponível no mercado nacional tem capacidade para $150 \mathrm{t} / \mathrm{dia}$, o que resultaria em longos períodos de ociosidade para municípios com geração de lixo muito inferior a esse limite. O equipamento seria, então, disponibilizado 
para atender outras demandas da localidade, ficando o aterro relegado a segundo plano (BARBOSA, 2004).

Foi possível observar também que há carência de tratamento de água e de esgoto, de incinerador e de captação de metano para produção de energia a partir do próprio aterro, condições essas que contribuiriam para que o mesmo seja eficiente e sustentável. Outro fator limitante é que todos os resíduos são cobertos, não existe um espaço para a sua triagem e, consequentemente, não há a reutilização e a redução dos resíduos no aterro, o que diminui sua vida útil e a possibilidade de uso com fonte de energia.

Segundo Monteiro e Zveibil (2001) a disponibilidade de infraestrutura na área escolhida reflete na redução de gastos de investimento em abastecimento de água, coleta e tratamento de esgotos, drenagem de águas pluviais, distribuição de energia elétrica e telefonia. Desses itens, a energia elétrica é o de maior relevância em termos ambientais mundiais (MASSUNARI, 2000).

\section{Caraterização dos trabalhadores}

A equipe do Aterro Sanitário de Sobral é composta por 11 funcionários: 09 garis, um coordenador e um gerente, que realizam os serviços e a manutenção do mesmo. Observa-se, então, um número reduzido de funcionários. Todos são do sexo masculino, a faixa etária varia de 16 a 55 anos e a maioria, com como pode ser visto no quadro 1, tem baixo nível de escolaridade, pois 7 (sete) possuem ensino fundamental incompleto.

Quadro 1. Grau de escolaridade dos profissionais no aterro sanitário do município de Sobral - Ceará- Brasil, 2013

\begin{tabular}{|l|c|}
\hline \multicolumn{1}{|c|}{ Grau de escolaridade } & $\mathbf{N}^{\circ}$ de funcionários \\
\hline Ensino Fundamental Incompleto & 07 \\
\hline Ensino Médio Incompleto & 01 \\
\hline Cursou o Ensino Médio & 01 \\
\hline Total & $\mathbf{0 9}$ \\
\hline
\end{tabular}

Fonte: Elaborado pelos autores (2013).

Todos os profissionais possuem jornada diária de $08 \mathrm{~h}$, durante seis dias na semana. A metade, trabalha há mais de 10 anos no aterro de Sobral, como pode ser observado na figura 2 . 
Figura 2. Tempo de trabalho dos trabalhadores do aterro sanitário de Sobral/ CE

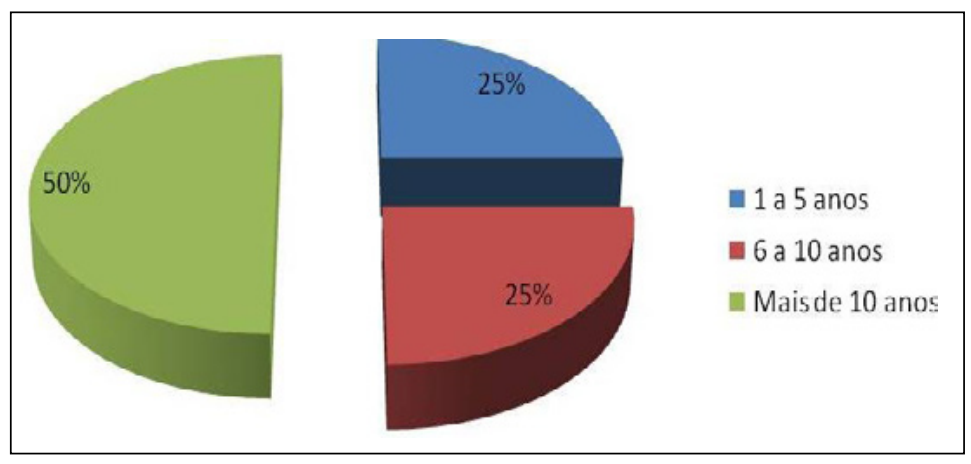

Fonte: Elaborado pelos autores (2013).

\section{Tipos de resíduos sólidos encontrados no aterro sanitário}

Segundos dados da Secretaria de Conservação e Serviços Públicos, o aterro tem na sua destinação final resíduos domiciliares, ramas, capina, lixo hospitalar, entulho, madeira, e outros (pneus, animais e peixes), sendo os resíduos de origem domiciliar os mais encontrados no aterro de Sobral/CE, conforme mostra o quadro 2 .

Quadro 2- Tipos de resíduos presentes no aterro de Sobral/CE - janeiro a outubro, 2013

\begin{tabular}{|l|l|l|l|l|l|l|l|l|}
\hline \multirow{2}{*}{ MESES } & $\begin{array}{c}\text { Resíduo } \\
\text { domiciliar } \\
\left(\mathrm{m}^{3}\right)\end{array}$ & $\begin{array}{c}\text { Resíduo } \\
\text { hospitalar } \\
\left(\mathrm{m}^{3}\right)\end{array}$ & $\begin{array}{c}\text { Capinação } \\
\left(\mathrm{m}^{3}\right)\end{array}$ & $\begin{array}{c}\text { Rama } \\
\left(\mathrm{m}^{3}\right)\end{array}$ & $\begin{array}{c}\text { Pneus } \\
(\text { Unid })\end{array}$ & $\begin{array}{c}\text { Coco } \\
\left(\mathrm{m}^{3}\right)\end{array}$ & $\begin{array}{c}\text { Animais } \\
(\text { Unid })\end{array}$ & $\begin{array}{c}\text { Animais } \\
(\mathrm{Kg})\end{array}$ \\
\hline Janeiro & 8.679 & 65 & 0 & 1.799 & 182 & 88 & 66 & 520 \\
\hline Fevereiro & 8.997 & 52 & 0 & 2.032 & 102 & 56 & 45 & 480 \\
\hline Março & 8.463 & 65 & 198 & 1.984 & 115 & 82 & 326 & 540 \\
\hline Abril & 7.307 & 74 & 336 & 1.869 & 130 & 0 & 148 & 500 \\
\hline Maio & 7.694 & 67 & 1.487 & 1.836 & 82 & 40 & 207 & 520 \\
\hline Junho & 7.391 & 56 & 1.124 & 2.005 & 116 & 60 & 112 & 440 \\
\hline Julho & 7.443 & 50 & 1.462 & 1.808 & 187 & 60 & 11 & 520 \\
\hline Agosto & 7.755 & 55 & 1.528 & 2.110 & 110 & 101 & 63 & 520 \\
\hline Setembro & 7.384 & 55 & 1.440 & 1.877 & 112 & 72 & 104 & 0 \\
\hline Outubro & 7.188 & 62 & 1.042 & 1.876 & 96 & 80 & 63 & 0 \\
\hline TOTAL & 78.301 & 601 & 8.617 & 19.196 & 1.232 & 639 & 1.145 & 4.040 \\
\hline
\end{tabular}

Fonte: Elaborado pelos autores com dados da Secretaria de Conservação e Serviços Públicos SERCOV, Sobral/CE, 2013. 
Quando perguntado aos profissionais quais os tipos de resíduos sólidos com que eles têm contato, $50 \%$ referiu a presença de resíduos de origem hospitalar, como pode ser visto na figura 3, e apenas $12 \%$ citaram os resíduos de origem domiciliar. De acordo com o IBGE (2013), a maior parte dos resíduos coletados pelos serviços públicos são de origem domiciliar, e o destino final desses resíduos é um aterro sanitário, visando à saúde da população e a atenção ao meio ambiente.

Figura 3. Tipos de resíduos sólidos presentes no aterro sanitário de Sobral/CE segundo os trabalhadores

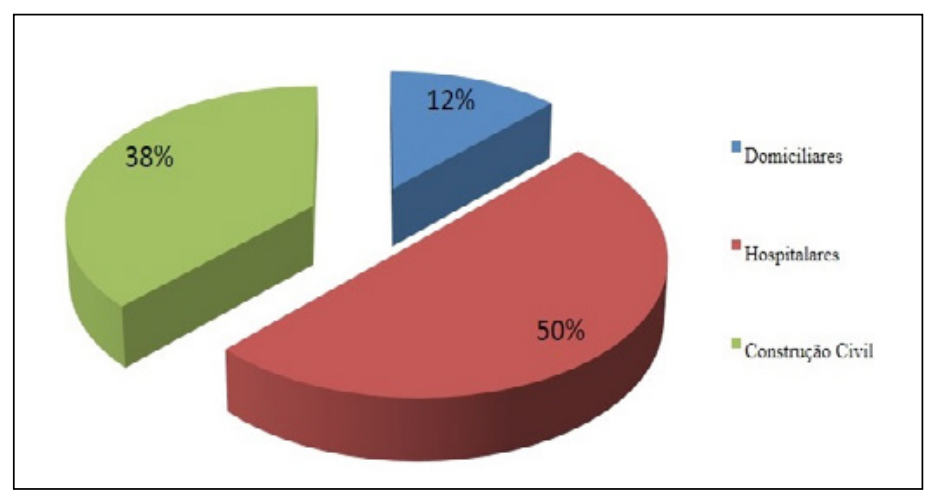

Fonte: Elaborado pelos autores (2013).

A resposta dos profissionais contradiz o que foi visto na visita in loco, uma vez que foi possível observar resíduos, preferencialmente domiciliares. Pode-se assim, analisar que a baixa escolaridade é um dos fatores que leva a falta de esclarecimento de como diferenciar os tipos de resíduos existentes, e consequentemente, as medidas preventivas a serem adotadas pelos trabalhadores em seu ambiente de trabalho. Lembrando que é responsabilidade do setor público a limpeza urbana, a coleta e o transporte, bem como a disposição final dos resíduos de origem domiciliar (EGREJA FILHO, 1996).

$\mathrm{Na}$ visita in loco foi observado também que resíduos hospitalares estavam dispostos junto aos domiciliares, pois luvas, seringas, agulhas e remédios estavam a céu aberto, expondo os trabalhadores a riscos biológicos e comprometendo sua saúde, como pode ser observado nas figuras $4 \mathrm{a}$ e $4 \mathrm{~b}$. 
Figura 4: Resíduos hospitalares fora da vala séptica, junto aos resíduos de origem domiciliar

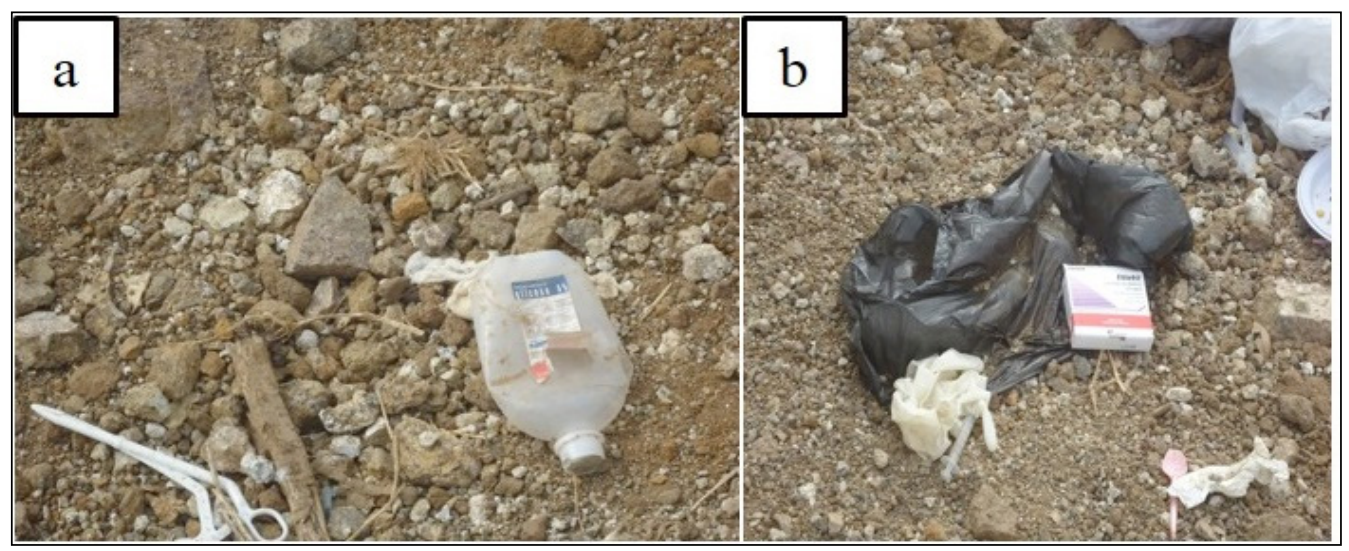

Legenda: a) Soro fisiológico e pinça descartável fora da vala séptica; b) Seringas descartáveis e medicamentos com resíduos domiciliares.

Fonte: Elaborado pelos autores (2013).

Segundo dados da Secretaria de Conservação e Serviços Públicos os resíduos hospitalares são coletados por veículo específico, sendo acondicionados em uma vala séptica, que são trincheiras escavadas no solo, com a largura igual à da lâmina do trator, altura entre 3,00 e 4,50 metros e dimensionadas para atender a uma geração periódica de resíduos (mensal, semestral e anual). Em seguida é procedida a impermeabilização do fundo e das laterais da trincheira escavada e é dado início à deposição dos resíduos, que são cobertos diariamente tanto na superfície superior, quanto no talude lateral.

Os resíduos sólidos oriundos dos serviços de saúde, apesar de representarem cerca de $1 \%$ da totalidade de resíduos gerados no meio urbano, oferecem um preocupante risco sanitário e ambiental perante um gerenciamento inadequado, pois são possíveis fontes de propagação de doenças, além de apresentarem um risco ocupacional intra e extra estabelecimento de saúde (SILVA; HOPPE, 2005). Os resíduos sólidos municipais contêm diversos microrganismos, uma vez que resíduos hospitalares como curativos, agulhas, seringas e luvas descartáveis são misturados a resíduos domiciliares como fraldas descartáveis, camisinha, papel higiênico e absorventes (OLIVEIRA; CASTRO; ZANDONADI, 2012).

\section{Riscos ocupacionais presentes no aterro sanitário}

Foram detectados 3 tipos de ricos ocupacionais presentes no aterro sanitário, além dos biológicos citados acima: físicos, ergonômicos e de acidentes. Inicialmente os trabalhadores foram questionados sobre o odor presente no ambiente de trabalho, $56 \%$ dos entrevistados referiram estar acostumados 
ao mau cheiro do lixo, porém $44 \%$ apresentaram/ainda apresentam cefaleias diárias, mal-estar e náuseas ao iniciar a jornada de trabalho, como pode ser observado na Figura 6.

Figura 6. Problemas relacionados ao odor de resíduos no ambiente de trabalho

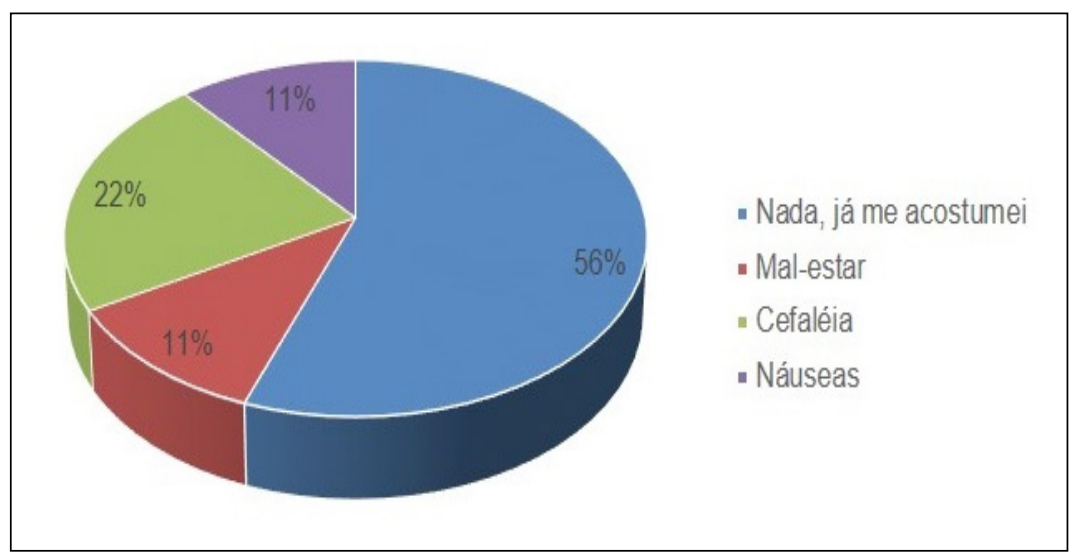

Fonte: Elaborado pelos autores (2013).

O odor vindo dos resíduos pode causar mal-estar, cefaleias e náuseas em trabalhadores e pessoas que se encontrem próximo ao sistema de manuseio, transporte e destinação final dos resíduos (OLIVEIRA; CASTRO; ZANDONADI, 2012).

Dentre os riscos físicos presentes no aterro destaca-se a poeira, os gases e vapores, o calor e os ruídos decorrentes do processo de manuseio, armazenagem e decomposição dos resíduos. O contato diário dos trabalhadores com os particulados suspensos no ar, especialmente as poeiras, é o principal fator de desconforto para $44 \%$ dos trabalhadores, devido ao risco de causar problemas no trato respiratório. Outros $22 \%$ estão incomodados com o calor. O mau cheiro, os ruídos e a necessidade de usar equipamento de proteção individual (EPI) causam desconfortos para 33\% dos trabalhadores, conforme pode-se observar na Figura 7. 
Figura 7. Incômodos diários em serviço dos trabalhadores do aterro sanitário de Sobral/CE

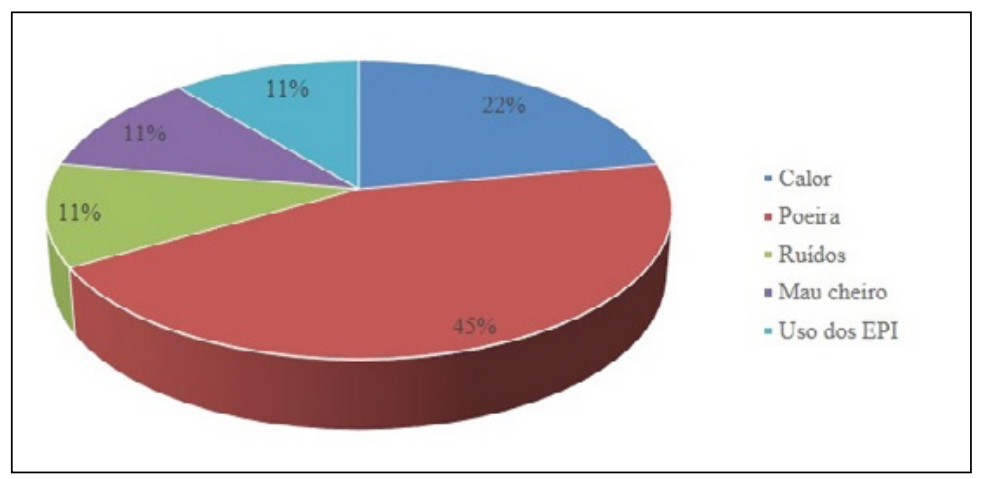

Fonte: Elaborado pelos autores (2013).

Os trabalhadores estão expostos a poeiras ocasionadas pela movimentação dos resíduos e do escapamento das máquinas, o que se agrava em períodos de estiagem. A poluição gerada pelos veículos também é fator relevantes à saúde dos trabalhadores, uma vez que doenças respiratórias são as mais comuns neste período. A poeira é responsável pelo desconforto e perda momentânea da visão, além de problemas respiratórios e pulmonares (OLIVEIRA; SANTOS, 2009).

A exposição ao sol e elevadas temperaturas causa risco de insolação e desidratação nos trabalhadores, sendo constantes no aterro. As temperaturas podem atingir entre 45 a $50^{\circ} \mathrm{C}$ no local onde ocorre a cobertura do lixo no período de estiagem, aumentando as chances dos trabalhadores de terem câncer de pele e outras doenças relacionadas. Além disso, foi percebido in loco a presença de ruído decorrente da operação das máquinas. Durante o processo de trabalho, a pá carregadeira e o trator esteira são acionados e usados frequentemente, ocasionando ruído que se soma aos ruídos produzidos no ambiente de trabalho.

Os trabalhadores do aterro sanitário, por realizarem suas atividades ao ar livre, ficam expostos ao calor, ao frio, à chuva, às variações bruscas de temperatura, além dos ruídos em excesso, que promovem a perda parcial ou permanente da audição, causam cefaleia, tensão nervosa e estresse (OLIVEIRA; CASTRO; ZANDONADI, 2012).

$\mathrm{Na}$ identificação dos riscos ergonômicos, 45\% dos entrevistados apresentam má postura no trabalho decorrente do manuseio do maquinário (pá carregadeira, trator esteira reto escavadeira ou caçambas) e da retirada e manuseio dos resíduos oriundos das caçambas. Além disso, 33\% dos trabalhadores citou que possui risco de quedas no trabalho e $11 \%$ de atropelamento. A figura 8 apresenta esses percentuais. 
Figura 8. Riscos ergonômicos presentes no aterro sanitário de Sobral/CE

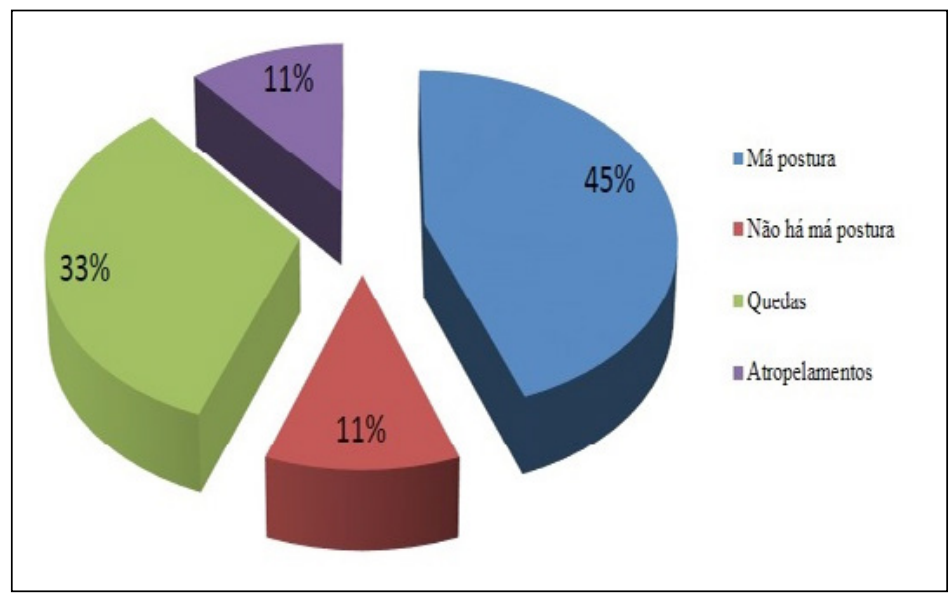

Fonte: Elaborado pelos autores (2013).

A má postura adotada no trabalho e os movimentos repetitivos também estiveram presentes no estudo de Motta (2000). Na pesquisa do SIEMACO (2011), 24\% dos trabalhadores apresentaram adoecimento envolvendo distúrbios osteomusculares.

Riscos ergonômicos são frequentes nos ambientes de trabalho. Neste estudo, o serviço público responsável pelo aterro não está em conformidade com o que prevê a Norma Regulamentadora - NR17. A Norma visa estabelecer parâmetros que permitem a adaptação das condições de trabalho às condições psicofisiológicas do trabalhador, de modo a proporcionar um máximo de conforto, segurança e desempenho eficiente dos mesmos, embasados juridicamente pelos artigos 198 e 199 da Consolidação de Leis Trabalhistas - CLT (MINISTÉRIO DO TRABALHO E EMPREGO, 2013), o que não foi observado no local de estudo.

Por fim, foi verificada a frequência com ocorrem acidentes de trabalho no aterro envolvendo materiais perfurocortantes, como objetos ou vidros. $25 \%$ dos trabalhadores referiu acidentar-se uma vez por mês, $12,5 \%$ uma vez por semana e outros $12,5 \%$ mais do que três vezes por semana, conforme pode ser observado na Figura 9. Os acidentes ocorrem durante o manuseio e o transporte diário dos resíduos. Para Oliveira, Castro e Zandonadi (2012) a relação entre movimentos repetitivos e exposição à materiais perfurocortantes com cansaço físico e mental são fortes aliados dos acidentes de trabalho. 
Figura 9. Frequência de acidentes com material perfurocortante

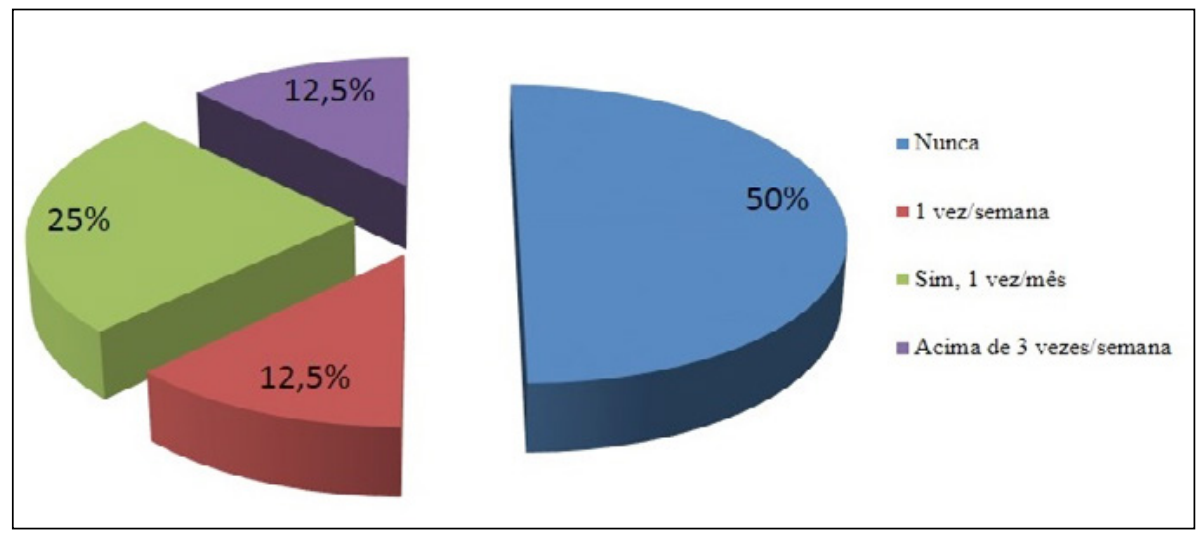

Fonte: Elaborado pelos autores (2013).

Felizmente $50 \%$ dos trabalhadores referiu não tem o contato direto com objetos cortantes, uma vez que os mesmos são manuseados por meio do maquinário, condição que os protege deste tipo de acidente.

\section{Doenças adquiridas pelos trabalhadores do aterro sanitário}

Os trabalhadores foram questionados sobre seu histórico de adoecimento. Conforme a Figura 5, todas as patologias, sinais e sintomas referidos pelos entrevistados possuem relação com sua atividade laboral. Nota-se que $45 \%$ (04) dos entrevistados referiram ter dor na coluna e os nos braços, o que sugere o comprometimento da integridade física dos mesmos e o surgimento de complicações futuras decorrentes das atividades desempenhada no aterro, inclusive com aposentadoria prematura. A maioria das doenças que surgem nesse tipo de trabalho estão relacionados aos riscos ergonômicos decorrentes do esforço físico, muitas vezes repetitivo, sendo a dor proveniente destas ações (TAKEDA, 2010). 
Figura 5. Doenças adquiridas pelos trabalhadores em seu ambiente de trabalho

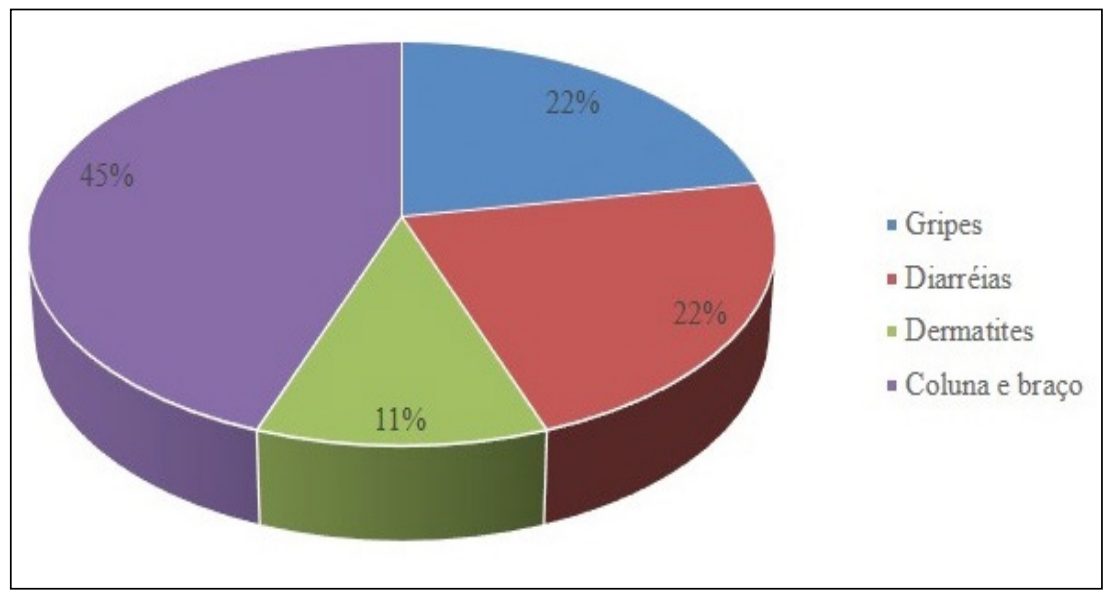

Fonte: Elaborado pelos autores (2013).

Para diminuir os riscos de doenças no ambiente de trabalho, a sugestão seria adotar a Norma Regulamentadora - NR4, que trata de Serviços Especializados em Engenharia de Segurança e Medicina do Trabalho (SESMT), que estabelece a obrigatoriedade de as empresas públicas e privadas promoverem a saúde e proteger a integridade do trabalhador no local de trabalho, embasados juridicamente pelo artigo 162 da Consolidação de Leis Trabalhistas - CLT (MINISTÉRIO DO TRABALHO E EMPREGO, 2013).

\section{Uso de Equipamentos de Proteção Individual e capacitação dos profissionais}

Durante o estudo, percebeu-se que $100 \%$ dos trabalhadores não utilizam diária e corretamente todos os EPI (botas, luvas, óculos, protetor auricular, capacetes e uniformes) necessários a sua saúde e segurança no trabalho. Além disso, os trabalhadores afirmaram não dispor de todos os EPI no aterro, como no caso do protetor auditivo e capacete. Por outro lado, verificou-se que os trabalhadores não fazem uso dos EPI por não gostarem ou se sentirem incomodados com os mesmos, conforme referido anteriormente.

A figura 10 , a seguir, demonstra que $45 \%$ dos trabalhadores não utilizam uniforme e botas; $35 \%$ não utilizam botas e luvas; 11 não utilizam botas, luvas e uniforme e o mesmo percentual não faz uso de luvas, óculos, protetor auricular, botas e uniforme. 
Figura 10. Tipos de EPI não utilizados pelos profissionais do aterro sanitário

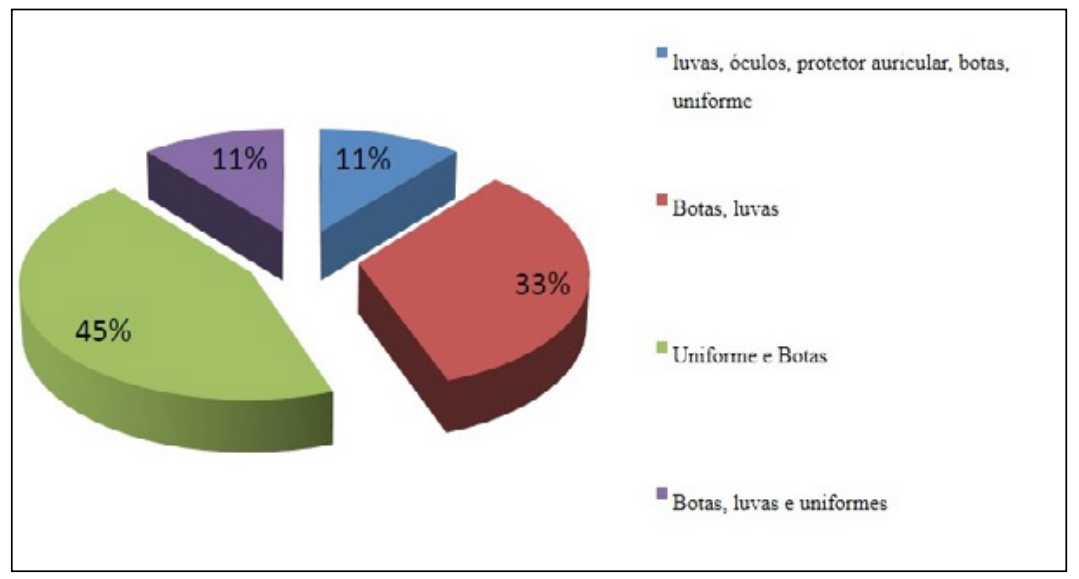

Fonte: Elaborado pelos autores (2013).

As NR6 e NR26 preveem a obrigatoriedade de fornecimento de EPI pelo empregador aos empregados sempre que as condições de trabalho assim exigirem, bem como o uso dos mesmos pelos trabalhadores, embasados juridicamente pelos artigos 166, 167 e 200 da CLT, respectivamente (MINISTÉRIO DO TRABALHO E EMPREGO, 2013). Portanto, os profissionais do aterro estão em desacordo com as referidas normas regulamentadoras.

$\mathrm{Na}$ visita in loco foi verificada a intensidade do ruído produzido no aterro, utilizando-se para isso o aparelho Decibelímetro Digital Impac IP-170L, de calibração de $94 \mathrm{~dB}$ em $1 \mathrm{Khz}$, o qual apresentou resultados entre 95 a 120 decibéis. Segundo a NR 15 (Atividades e Operações Insalubres) o máximo de exposição diária permissível é de 85 decibéis com uma jornada de trabalho de 8 horas diárias (MINISTÉRIO DO TRABALHO E EMPREGO, 2013). Nesta ocasião, observou-se que somente um profissional utilizava o protetor auditivo, comprado por ele. O referido EPI é necessário, já que o ruído existente no ambiente de trabalho extrapola o valor tolerado pelo organismo. Apesar desse risco, o serviço público responsável não forneceu o protetor auditivo.

Após a identificação e análise dos fatores nocivos à saúde dos trabalhadores presentes no aterro sanitário, os mesmos foram repassados ao gestor. Com isso, viu-se a necessidade da atuação conjunta entre trabalhadores e o órgão público que coordena o serviço, com vistas à adoção de medidas para a prevenção de acidentes e promoção da saúde no trabalho. Assim, foi realizada uma capacitação, que pode ser vista nas figura12a e 12b, dirigida aos profissionais do aterro sobre os tipos de resíduos, uso dos EPI e a importância dos mesmos, além de ser fornecidas informações acerca dos esforços físicos e mentais tolerados no trabalho, os riscos ocupacionais presentes no aterro e formas de prevenção, os direitos e deveres dos trabalhadores e os cuidados 
para a promoção e manutenção da saúde dos profissionais que trabalham com a destinação final dos resíduos.

Figura 11: Capacitação dos trabalhadores que atuam no aterro sanitário de Sobral/CE, 2013

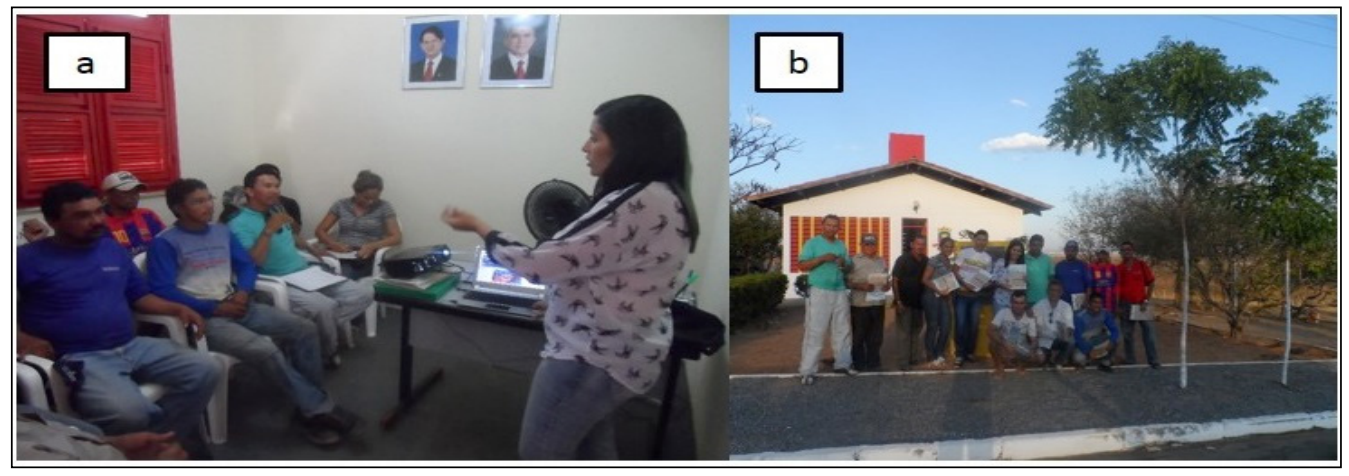

Legenda: a) orientação sobre os tipos de resíduos sólidos e a importância do uso dos EPI; b) momento de capacitação para os profissionais do aterro sanitários.

Fonte: autoria própria (2013).

\section{CONCLUSÃO}

Os trabalhadores do aterro sanitário de Sobral/CE estão expostos a vários riscos ocupacionais no ambiente de trabalho, entre eles os biológicos, físicos, ergonômicos e de acidente, típicos da atividade laboral exercida no local. Tais riscos podem ser minimizados ou agravados, de acordo com as atitudes tomadas tanto pelos trabalhadores quanto pelo poder público responsável pelo serviço. Neste estudo, constatou-se que há falta de EPI no local, os quais auxiliariam na melhoria das condições de trabalho.

Verificou-se também que os trabalhadores não fazem uso dos EPI por se sentirem desconfortáveis com eles. Pode-se inferir que a falta de conscientização desses trabalhadores sobre a necessidade de utilizar tais equipamentos como forma de prevenção de agravos à saúde decorrentes da atividade laboral, pode reduzir a aquisição dos mesmos por parte do poder público, gerando um círculo vicioso que mantém e reforça as condições insalubres existente no local. Reforça-se a necessidade de oportunizar atividades educativas continuadas com esses trabalhadores, sejam formais ou informais, em forma de roda de conversa, para que os mesmos possam expressar a sua percepção sobre o trabalho que realizam.

A disposição de resíduos hospitalares junto aos domiciliares presente no aterro sanitário é inadequada e revela uma situação grave e alarmante, que complexifica as condições laborais, que por sua natureza, são desgastantes. Há necessidade de intervenção junto aos serviços de saúde e comunidade em 
geral, com ações que promovam educação ambiental, especialmente sobre a correta segregação dos diferentes tipos de lixo existentes.

Para maior proteção dos trabalhadores do aterro sugere-se a criação de uma Comissão Interna de Prevenção de Acidentes (CIPA), conforme a NR 5, que estabelece a obrigatoriedade das empresas públicas e privadas organizarem e manterem em funcionamento, por estabelecimento e constituída exclusivamente por empregados, com o objetivo de prevenir infortúnios laborais. Por meio dessa comissão o trabalhador poderá apresentar formalmente sugestões e recomendações ao empregador para que melhore as condições de trabalho e assim possa minimizar as possíveis causas de acidentes do trabalho e doenças ocupacionais.

\section{REFERÊNCIAS}

ABEQ, Associação Brasileira de Engenharia Química. Lixão afeta meio ambiente em todo o estado de Alagoas, 2001.

BARBOSA, L.T. Gerenciamento de Resíduos Sólidos Urbanos no norte de Minas Gerais: Estudo relativo à implantação de unidades de reciclagem e compostagem a partir de 1997. Escola de Engenharia da UFMG. Belo Horizonte, 2004.

BRASIL. [Lei n. 12.305, de 2 de agosto de 2010]. Política nacional de resíduos sólidos [recurso eletrônico]. - 2. ed. - Brasília: Câmara dos Deputados, Edições Câmara, 2012. 73 p. - (Série legislação ; n. 81).

Ministério do Trabalho e Emprego. Portaria MTE N. ${ }^{\circ} 485$ das Normas

Regulamentadoras - Segurança e Saúde do Trabalho. Brasília: Ministério do Trabalho e Emprego, 2015.

CORREA, J., LANÇA, S. S. B. Resíduos Sólidos - Projeto, Operação e Monitoramento de Aterros Sanitários - Guia do profissional em treinamento. Cátedra da Unesco de Educação à Distância - FAE/UFMG. Editora Sigma, 2008.

EGREJA FILHO, F. B. Relatório de atividades de consultoria junto à Superintendência de Limpeza Urbana de Belo Horizonte. Belo Horizonte: [s.n.], 1996.

FERREIRA, J.A., ANJOS, L.A. Aspectos de saúde coletiva e ocupacional associados à gestão dos resíduos sólidos municipais. Caderno de Saúde Pública, Rio de Janeiro, 2005.

INSTITUTO BRASILEIRO DE GEOGRAFIA E ESTATÍSTICA-IBGE. Distribuição espacial e nível de abrangência das redes de saneamento. Disponível em:http:/ / www.ibge.gov.br/home/estatistica/populacao/atlas_saneamento/pdfs/cap01.pdf. Acesso em: 07 jul. 2013.

. Resultados do Censo 2010. Pernambuco, 2010. 
KUPCHELLA, C. D. \& HYLAND, M.C. Environmental Science - Living Within the System of Nature. London: Prentice-Hall International, 1993

LAKATOS, Eva Maria; MARCONI, Marina de Andrade. Fundamentos de metodologia científica. 7. ed. São Paulo: Atlas, 2010.

MASSUNARI, I.S. Pesquisa e Seleção de Áreas para Aterro Sanitário. Ed. 54. p. 17 -22. ABPL - Associação Brasileira de Resíduos Sólidos e Limpeza Pública. Revista Limpeza Pública, Acervo digital. 2000.

MINAYO, M. C. S., DESLANDES, S.F. Pesquisa social - Teoria, Método e Criatividade. $28^{\circ}$ ed. Rio de Janeiro: Editora Vozes, 2009.

MINISTÉRIO DO TRABALHO E EMPREGO. Segurança e Saúde no Trabalho. Disponível em: <http://www.mte.gov.br/seg_sau/default.asp> Acesso em: mai. 2013.

MONTEIRO, J.H.R.P.; ZVEIBIL, V.Z. Manual de Gerenciamento Integrado de Resíduos Sólidos. IBAM, Rio de Janeiro, 2001.

MOTTA, G. M. V. De lixeiro a agente de limpeza urbana: um estudo sobre saúde mental e trabalho. Monografia de conclusão do curso não publicada, Centro Universitário Newton Paiva, Belo Horizonte, 2000.

NEVES, G.S. A realidade do trabalhador de limpeza pública em Florianópolis. UDESC - Centro de Ciências da Educação. Curso de Graduação - Especialização em Políticas Públicas, 2003.

OLIVEIRA, G.A., SANTOS, H.I. Avaliação da Saúde Ocupacional dos Garis de Hidrolândia, Goiás. Monografia - Universidade Católica de Goiás, 2009.

OLIVEIRA, A. P. S.; ZANDONADI, F. B.; CASTRO, J. M. Riscos Ocupacionais entre trabalhadores catadores de materiais recicláveis em vazadouro a céu aberto (lixão) no município de Sinop/MT - um estudo de caso. 2012. [Especialização em Engenharia de Segurança do Trabalho] - Universidade de Cuiabá. Cuiabá: UNIC, 2012.

OLIVEIRA, A. P. S.; ZANDONADI, F. B.; CASTRO, J. M. Avaliação dos riscos ocupacionais entre trabalhadores da coleta de resíduos sólidos domiciliares da cidade de Sinop - MT: um estudo de caso. 2012. Artigo [Especialização em Engenharia de Segurança do Trabalho]-Universidade de Cuiabá. Cuiabá: UNIC, 2012.

SIEMACO, Sindicato dos Trabalhadores em Empresas Prestação de Serviço de Asseio e Conservação e Limpeza Urbana de São Paulo. Perfil dos Trabalhadores em Asseio e Conservação e Limpeza de São Paulo. São Paulo: SIEMACO, 2011.

SILVA C.E., HOPPE A.E. Diagnóstico dos Resíduos de Serviço de Saúde no Interior do Rio Grande do Sul. Revista engenharia sanitária e ambiental; 10(2):146-151, 2005. 
SILVA, N. L. S. Aterro sanitário para resíduos sólidos urbanos - RSU- matriz para seleção da área de implantação. Monografia - Universidade Estadual de Feira de Santana, 2011.

SILVEIRA, I. S. F. Avaliação dos riscos ocupacionais na coleta de resíduos sólidos domiciliares de Cuiabá/MT. Monografia - Universidade Federal de Mato Grosso, 2009.

SOBRAL, Secretaria de Habitação e Saneamento Básico. Plano de Gerenciamento Integrado de Resíduos Sólidos Urbanos do Município de Sobral/CE. Sobral, abril de 2009.

TAKEDA, F. Configuração Ergonômica do Trabalho em Produção Contínua: O Caso de Ambiente de Cortes em Abatedouro de Frangos. Dissertação (Mestrado em Engenharia de Produção) - Universidade Tecnológica Federal do Paraná. Ponta Grossa, 2010. 